\title{
Effect of temperature (cooking and freezing) on the concentration of oxytetracycline residue in experimentally induced birds
}

\author{
Ezenduka Ekene Vivienne, Okorie-kanu Onyinye Josephine and Nwanta John Anaelom
}

Department of Veterinary Public Health and Preventive Medicine, University of Nigeria, Nsukka, Nigeria.

Corresponding author: Ezenduka Ekene Vivienne, e-mail: ekene.ezenduka@unn.edu.ng

Co-authors: 0OJ: onyinye.okoro@unn.edu.ng, NJA: john.nwanta@unn.edu.ng

Received: 13-10-2017, Accepted: 08-01-2018, Published online: 10-02-2018

doi: 10.14202/vetworld.2018.167-171 How to cite this article: Vivienne EE, Josephine OO, Anaelom NJ (2018), Effect of temperature (cooking and freezing) on the concentration of oxytetracycline residue in experimentally induced birds, Veterinary World, 11(2): 167-171.

\begin{abstract}
Aim: The objective of this study was to determine the effect of varying temperatures (different cooking methods and freezing) on the concentration of oxytetracycline (OTC) residues in tissues of broiler birds.

Materials and Methods: Fifty, 5 -week-old birds were purchased and acclimatized for 3 weeks while being fed antibiotic-free feed and water. Four birds were then tested for residue and in the absence; the remaining birds were injected intramuscularly with oxytetracycline at its therapeutic dose. Muscle and liver samples of the treated birds were harvested and checked for OTC residues before subjecting them to boiling, microwaving, and roasting. The three plate test was used for the residue detection.

Result: OTC was detected at both $\mathrm{pH} 6.0$ and $\mathrm{pH} 7.2$ but not detected at $\mathrm{pH}$ 8.0. Roasting and boiling significantly reduced the concentration of oxytetracycline in muscle by $53.6 \%$ and $69.6 \%$, respectively, at $\mathrm{pH} 6.0$, microwaving reduced the concentration by $49.1 \%$ but was not statistically significant. The same pattern was followed at $\mathrm{pH} 7.2$ with reduction of $34.3 \%, 53.2 \%$, and $67.7 \%$ for microwaved, roasted, and boiled. For the liver tissues, there was a significant reduction in the concentration for both $\mathrm{pH}$ : 6.0 (57.75\%, 79.75\%, and 89\%; $\mathrm{pH} 7.2(48.06 \%, 79.6 \%$, and $88.79 \%)$ for boiled, microwaved, and roasted samples. Boiling had a greater reduction effect for muscle samples while roasting had a greater reduction in liver samples at both pHs. Freezing at $-10^{\circ} \mathrm{C}$ had no effect on the concentration of OTC even after 9 days.
\end{abstract}

Conclusion: The significant reduction of OTC concentration by cooking indicates that consumers may not be at risk of the effects of OTC residues in meat, but microwaving meat may not reduce the concentration below the maximum residue limit if the initial concentration is very high. Therefore, routine monitoring of drug residues in farms and abattoirs is still advocated.

Keywords: antimicrobials, cooking methods, drug residue, oxytetracycline.

\section{Introduction}

Antimicrobials are widely used in livestock, and poultry production for the purposes of prevention and treatment of diseases and growth promotion [1,2] and the tetracyclines (TCs) are ranked among the frequently used $[3,4]$. These drugs accumulate in tissues and eggs as residues if the withdrawal periods are not observed before slaughter or before egg collection. Residues of these drugs are of public health importance because of the deleterious effect they have in humans. Some of these effects include development of resistant strains of microorganisms, allergy, autoimmunity, and nephrotoxicity which can be particularly caused by gentamicin and distortion of the microflora [5]. Some of the drugs have been banned for use in food animals especially furazolidone and

Copyright: Vivienne, et al. Open Access. This article is distributed under the terms of the Creative Commons Attribution 4.0 International License (http://creativecommons.org/licenses/ by/4.0/), which permits unrestricted use, distribution, and reproduction in any medium, provided you give appropriate credit to the original author(s) and the source, provide a link to the Creative Commons license, and indicate if changes were made. The Creative Commons Public Domain Dedication waiver (http:// creativecommons.org/publicdomain/zero/1.0/) applies to the data made available in this article, unless otherwise stated. chloramphenicol because of their mutagenic and bone marrow toxicity effect, respectively.

The European four plate test is a reference microbiological method for the detection of antimicrobial residues in foods of animal origin. It is said to be semi-quantitative because it can detect different classes of antimicrobials. As the name implies, it consists four different test plates seeded with Bacillus subtilis and Micrococcus luteus at different $\mathrm{pH}$ levels (pH 6.0, 7.2, and 8.0). $\mathrm{pH} 6.0$ best detects beta-lactams and TCs, $\mathrm{pH} 7.2$ best detects sulfonamides, and pH 8.0 best detects aminoglycosides while $\mathrm{pH} 8.0$ seeded with $M$. luteus best detects macrolides [6,7].

In developed countries, many researchers have been interested in evaluating whether antibiotic residues can be destroyed by cooking procedures, pasteurization, or canning processes [8-12]. Traditionally, heat stability of antibiotics has been studied based on a change in concentration using microbiological test methods. Few studies evaluating the heat stability of veterinary drug residues have been carried out using both microbiological and immunoassay methods [13]. Previous studies have suggested that sulfamethazine, oxacillin, chloramphenicol, aminoglycosides, 
quinolones, clindamycin, novobiocin, trimethoprim, vancomycin, and azlocillin are heat-stable $[9,14,15]$, while oxytetracycline (OTC) and erythromycin were shown to be heat-labile [11]. On the other hand, several $\beta$-lactams such as penicillin $\mathrm{G}$, ampicillin, and amoxicillin appear partially heat-labile [14]. Antibiotics of the same class were also reported to show different heat stability depending on different matrices and heating treatments involved $[13,16,17]$.

Since meat is always heated before consumption, few reports have been published about the effect of heating on the stability of TCs residues in chicken. The fate of drug residues during heat processing is, however, unclear. Although freezing is a form of preservation method of meat by impeding the growth of microorganisms, the fate of antimicrobial residues concentration when frozen with time is unknown. This study will thus investigate the effect of heat treatment and freezing on OTC residues in liver and muscle tissues of broiler chicken using the three plate test (TPT), a microbiological method of detection. The TPT, also a type of plate test was chosen for the study since the focus antimicrobial is OTC belonging to the class of TC and they are best detected with B. subtilis at pH 6.0.

\section{Materials and Methods}

\section{Ethical approval}

This study was conducted in accordance with the Ethics and Regulation Guiding the Use of Animals as approved by the University of Nigeria, Nsukka.

\section{Study design}

Fifty, 5-week-old broilers were bought from a major poultry farmer. The birds were fed ad libitum with antimicrobial free feed and water for 3 weeks. After the 3 weeks waiting period, 4 birds were slaughtered and the breast muscles and liver were collected as post-slaughter sample matrix. The samples were tested for the presence of antimicrobial residues using TPT. All the samples from the four birds were tested negative for antimicrobial residues.

\section{Experimental drug administration}

In the absence of antimicrobial residues in the birds after the waiting period, the birds were injected intramuscularly at the breast muscle with long-acting OTC (Coophavet, France) at the label therapeutic dose of $20 \mathrm{mg} / \mathrm{kg}$ body weight.

\section{Testing for OTC residue in experimental birds}

After $24 \mathrm{~h}$ post drug administration, 2 birds were slaughtered daily, the liver and muscle harvested, extracted and tested for residue until no residue was detected in the organs.

\section{Sample preparation/organ juice extraction}

$5 \mathrm{~g}$ of each organ sample (raw and heat treated) was macerated using sterile pestle and mortar, emulsified with $5 \mathrm{ml}$ of distilled water and centrifuged at $5000 \mathrm{rpm}$ for $10 \mathrm{~min}$ as described by Nonga et al., 2009 [18]. The supernatant was decanted into
Eppendorf tubes and stored for analysis. All the positive tissues with high concentration of OTC residue were grouped into four parts; the first part was analyzed for the effect of freezing and the remaining three parts for the effect of heat treatment (boiling, microwaving, and roasting).

\section{Effect of heat treatment}

$10 \mathrm{~g}$ each of all the positive liver and muscle tissues were weighed before heat treatment.

\section{Boiling}

The weighed samples were placed into a strainer, immersed in $10 \mathrm{ml}$ of water bath preheated to $100^{\circ} \mathrm{C}$ and cooked for $30 \mathrm{~min}$ and allowed to cool before meat juice extraction.

\section{Roasting}

The weighed samples were placed on a metal baking tray and cooked to well done in an electric oven at $200^{\circ} \mathrm{C}$ for $30 \mathrm{~min}$ and allowed to cool before extraction.

\section{Microwaving}

The sample portion was placed in the microwave and cooked under full power $(900 \mathrm{~W})$ for $3 \mathrm{~min}$, removed, and allowed to cool before extraction. All the heat-treated samples were tested for residue.

\section{Effect of freezing on OTC residue}

A portion of the positive samples were kept frozen at $-10^{\circ} \mathrm{C}$ and tested for residue first after $24 \mathrm{~h}$, and subsequently, every 3 days for 10 days.

\section{OTC residue testing}

This was done using the TPT as described by Heitzman 1994 [6], with B. subtilis (BGA), Merck, Darmstadt, and Germany) as the test organism and Mueller-Hinton agar (Oxoid) as the medium. Susceptibility of the organism; $B$. subtilis was tested with commercially produced antibiotic discs of the TCs using Kirby and Bauer disc diffusion methods of determining susceptibility as per recommendation of Clinical Laboratory Standard Institute [19]. Three batches of Mueller-Hinton agar broth were prepared and adjusted to $\mathrm{pH} 6.0$ and 7.2 with dilute sulfuric acid $\left(\mathrm{H}_{2} \mathrm{SO}_{4}\right)$ and to 8.0 with sodium hydroxide $(\mathrm{NaOH})$. The adjusted media were sterilized and poured into sterile Petri dishes and allowed to gel. Each plate was seeded with $B$. subtilis. 3 wells were bored on each agar plate. $80 \mu 1$ of the organ extracts (liver and muscle) were inoculated in 2 wells, each well representing an organ, the remaining well was inoculated with 80 $\mu l$ of distilled water as negative control. The plates were incubated at $30^{\circ} \mathrm{C}$ for $18-24 \mathrm{~h}$, clear zone of inhibition with annular diameter $\geq 2 \mathrm{~mm}$ indicates positive for OTC [5].

\section{Statistical analysis}

Data from the study were analyzed in GraphPad Prism Statistical software version 5.02 (www.graphpad.com). 2 sample t-test was used to compare the 
mean values of raw samples and the different cooking methods while analysis of variance (ANOVA) was used to compare the mean values of the freezing times. The alpha value of significance was set at the $p$ level of $<0.05$.

\section{Result}

The isolate (B. subtilis) was susceptible to all the antimicrobials tested including OTC. All the positive samples with diameters above $4 \mathrm{~mm}$ were used. This means that the positive samples used were above the maximum residue limit (MRL) of OTC.

Table-1 summarizes the effect of different cooking methods on the concentration of OTC residues in muscles tissue using TPT at $\mathrm{pH}$ 6.0. The mean inhibition zones of raw muscles $(7 \mathrm{~mm})$ at $\mathrm{pH} 6.0$ were significantly $(\mathrm{p} \leq 0.05)$ reduced in boiled $(2.13 \mathrm{~mm})$ and roasted $(3.25 \mathrm{~mm})$ samples with $69.57 \%$ and $53.57 \%$ reductions, respectively. The $49.14 \%$ reduction by microwaving $(3.56 \mathrm{~mm})$ was not statistically significant.

Table-2 summarizes the effect of the cooking methods on OTC residue in muscle at $\mathrm{pH}$ 7.2. There was no statistical differences $(\mathrm{p}>0.05)$ in the mean values of raw $(7 \mathrm{~mm})$ and microwaved $(3.94 \mathrm{~mm})$ with $34.33 \%$ reduction. Statistical differences were observed between raw versus roasted $(2.81 \mathrm{~mm})$ and raw versus boiled $(1.94 \mathrm{~mm})$ muscle samples with $53.7 \%$ and $67.99 \%$, respectively.

Table-3 summarizes the effect of different cooking methods on the concentration of OTC residues in liver tissues at $\mathrm{pH}$ 6.0. The mean inhibition zone of raw $(4.0 \mathrm{~mm})$ liver at $\mathrm{pH} 6.0$ was significantly $(\mathrm{p} \leq 0.05)$ reduced by the three cooking methods at $57.73 \%, 79.75 \%$, and $89 \%$ for boiled, microwaved, and roasted, respectively.

Table-4 summarizes the effect of cooking methods on OTC residue in liver at $\mathrm{pH}$ 7.2. The mean inhibition zone of raw liver was also reduced by all the cooking methods at $48.06 \%, 79.63 \%$, and $88.79 \%$ for boiled, microwaved, and roasted, respectively.

For the effect of freezing time on OTC concentration in muscle and liver tissues at both $\mathrm{pH}$, at $\mathrm{pH}$ 6.0, muscle sample with initial mean inhibition zone of 5.81 changed to $5.81,5.72$, and 5.71 ; at $\mathrm{pH} 7.2$, the initial mean inhibition zone change from $6.0 \mathrm{~mm}$ to $6.0,6.2$, and 6.0 at the $3^{\text {rd }}, 6^{\text {th }}$, and $9^{\text {th }}$ days of freezing, respectively. The same pattern was followed for liver samples. There was little or no reduction in the mean concentrations of freezing in both tissues at different time intervals. The summary of the effect is shown in Figure-1.

\section{Discussion}

The effect of cooking procedures on OTC in poultry was determined by TPT. The TPT, a variant of the four plate test (FPT) best detects the TCs at $\mathrm{pH} 6.0$ with $B$. subtilis as the test organism, but this study also found that the TCs are comfortably detected at $\mathrm{pH} 7.2$ as well. The inhibition zones noted in this work could be assumed to be at or above the violative level of

Table-1: Comparison of inhibition zones between raw muscles and different cooking methods at pH 6.0.

\begin{tabular}{|c|c|c|c|c|c|c|c|}
\hline Muscle & $\begin{array}{l}\text { Mean inhibition } \\
\text { zone }(\mathrm{mm})\end{array}$ & $\begin{array}{l}\text { Difference } \\
\text { from raw }\end{array}$ & $\begin{array}{c}(\%) \\
\text { different }\end{array}$ & SEM (+ or -$)$ & t-test & df & $\mathbf{p}$ \\
\hline Raw & 7.00 & - & - & 1.45 & - & - & - \\
\hline Microwaved & 3.56 & 3.44 & 49.14 & 1.11 & 1.88 & 14 & 0.081 \\
\hline Roasted & 3.25 & 3.75 & 53.57 & 0.92 & 2.00 & 14 & 0.047 \\
\hline Boiled & 2.13 & 4.87 & 69.57 & 0.76 & 2.00 & 14 & 0.010 \\
\hline
\end{tabular}

SEM $=$ Standard error of the mean

Table-2: Comparison of inhibition zones between raw muscles and different cooking methods at pH 7.2.

\begin{tabular}{lcccccccc}
\hline Muscle & Mean & $\begin{array}{c}\text { Difference } \\
\text { from raw }\end{array}$ & $\begin{array}{l}\text { (\%) different } \\
\text { SEM }\end{array}$ & t-test & df & p \\
\hline Raw & 6.00 & - & - & 1.169 & - & - & - \\
Microwaved & 3.94 & 2.06 & 34.33 & 1.49 & 1.09 & 14 & 0.290 \\
Roasted & 2.81 & 3.19 & 53.17 & 0.80 & 2.00 & 14 & 0.044 \\
Boiled & 1.94 & 4.06 & 67.66 & 0.57 & 3.00 & 14 & 0.007 \\
\hline
\end{tabular}

SEM $=$ Standard error of the mean

Table-3: Comparison of inhibition zones between raw liver and different cooking methods at pH 6.0.

\begin{tabular}{|c|c|c|c|c|c|c|c|}
\hline Muscle & Mean & $\begin{array}{c}\text { Difference from } \\
\text { raw }\end{array}$ & (\%) difference & SEM & t-test & df & $\mathbf{p}$ \\
\hline Raw & 4.00 & - & - & 0.63 & - & - & - \\
\hline Boiled & 1.69 & 2.31 & 57.75 & 0.75 & 2.37 & 14 & 0.032 \\
\hline Microwaved & 0.81 & 3.19 & 79.75 & 0.35 & 4.43 & 14 & 0.006 \\
\hline Roasted & 0.44 & 3.56 & 89.00 & 0.22 & 5.36 & 14 & 0.001 \\
\hline
\end{tabular}

SEM $=$ Standard error of the mean 
Table-4: Comparison of inhibition zones between raw Liver and different cooking methods at pH 7.2.

\begin{tabular}{lcccccccc}
\hline Muscle & Mean & $\begin{array}{c}\text { Difference } \\
\text { from raw }\end{array}$ & $\mathbf{( \% )}$ difference & SEM & t-test & df & p \\
\hline Raw & 4.91 & - & - & 0.61 & - & - & - \\
Boiled & 2.55 & 2.36 & 48.06 & 0.56 & 2.85 & 20 & 0.009 \\
Microwaved & 1.00 & 3.91 & 79.63 & 0.26 & 5.89 & 20 & $<0.001$ \\
Roasted & 0.55 & 4.36 & 88.79 & 0.64 & 6.78 & 20 & $<0.001$ \\
\hline
\end{tabular}

SEM $=$ Standard error of the mean

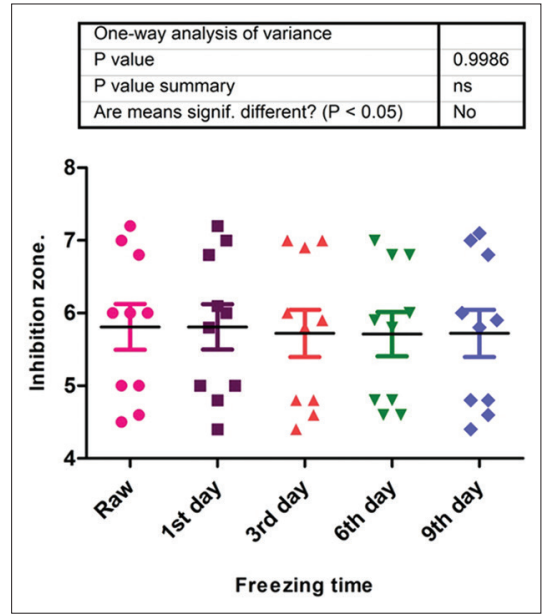

Figure-1: Effect of freezing on the concentration of oxytetracycline residue.

OTC because plate test with $B$. subtilis cannot detect residue when their concentrations are below or around the permissible limit $[7,5]$. The result for both $\mathrm{pHs}$ in muscle gave a net mean inhibitory zone of 34-69\% reduction with the statistically significant maximum $(69 \%)$ reduction shown by boiling and the minimum shown by microwaving. A similar work done by Javadi et a1. [20], on doxycycline, had a net decrease in mean inhibitory zones of 33-100\% with maximum and minimum inhibitory zone also shown by boiling and microwaving, respectively. Since the effect of an increase in cooking time was not done in this study, it may not be out of place to suggest that microwaving had the lowest decreasing effect on OTC concentration due to short cooking time.

The highest reduction of OTC in muscles by boiling in this study also agrees with the work of Rose et al. [17], with observed substantial net reductions in OTC of $35-94 \%$ and also in pig muscle with a net reduction of $48-60 \%$ [21]. The reduction of OTC in liver samples, on the other hand, had a higher net mean inhibitory reduction for both $\mathrm{pHs}$ at $58-89 \%$ with roasting having the highest reduction and boiling the least. Although Javadi et al. [20] had total (100\%) reduction of inhibitory zones for both muscle and liver samples at $\mathrm{pH} 6.0$ and 7.2, the mean inhibitory zones of the raw samples were $<2 \mathrm{~mm}$ in diameter, and so a complete clearance of residues was achieved. In this study, however, the least mean value of the samples was $4 \mathrm{~mm}$; therefore, there was no $100 \%$ clearance, this means that very high concentrations of OTC residues may not be reduced below the MRL by heating. Al-Ghamd et al. [22] also did not achieve complete clearance of OTC due to the initial high concentration of the raw samples.

The results of this study are consistent with several other studies that reported a decrease in antimicrobial residues concentrations in foods following heat treatment. Therefore, the possibility of reducing the apparent toxic effect of these drugs to consumers is increased. Reduction in TC concentrations during boiling was due to the migration of the TC from the meat to cooking medium (water) [9], while during the microwaving and roasting processes, reduction was due to juice exuding out from the meat. The overall loss of TC residues was due to denaturation of protein -TC compounds. From the safety and toxicological point of view, these findings show an additional advantage of cooking as a food processing method.

Cooking methods generally, can reduce the concentration of OTC in meat, boiling was more effective in reducing the concentration of OTC in muscle while roasting was more effective in reducing the concentration of liver samples. Since some of the reductions in OTC concentrations were not statistically significant, there is a possibility that their OTC concentrations after cooking, were still above the MRL. It is, therefore, better to prevent the occurrence of violative levels of drug residues in raw meats but where inevitable, cooking for a longer time should be explored.

\section{Authors' Contributions}

EEV planned, designed and carried out the work; OOJ was part of carrying out the work by raising the birds and involved in drug administration; NJA was part of the design and supervised the work. All authors read and approved the manuscript.

\section{Acknowledgments}

The authors are thankful to the lab scientists and attendants of the Veterinary Public Health and Preventive Medicine Laboratory, for their immeasurable assistance. There was no external funding. This study was funded by the authors.

\section{Competing Interests} interests.

The authors declare that they have no competing

\section{References}

1. Muhammad, D.M., Umair, H.K., Uruj, T.B. and Asad F. (2017) Antimicrobial drug residues in poultry products and 
implications on public health: A review Int. J. Food Props., 7(20): 1433-1446.

2. Sajid, A., Kashif, N., Kifayat, N. and Ahmad, S. (2016) Detection of antibiotic residues in poultry meat. Pak. J. Pharm. Sci., 29(5): 1691-1694.

3. Cetinkaya, F., Yibar, A., Soyutemiz, G.E., Okutan, B., Ozcan, A. and Karaca, M.Y (2012) Determination of tetracycline residues in chicken meat by liquid chromatography-tandem mass spectrometry. Food. Addit. Contam Part. B Surveill, 5(1): 45-9.

4. Ezenduka, E.V., Oboegbulem, S.I., Nwanta, J.A. and Onunkwo, J. (2011) Prevalence of antimicrobial residues in raw table eggs from farms and retail outlets in Enugu State, Nigeria. Trop. Anim. Health Prod., 43: 557-555.

5. Myllyniemi, A.L., Nuotio, L., Lindfors, E., Rannikko, R., Niemi, A., Backman, C.A. (2001) Microbial six-plate method for the identification of certain antibiotic groups in incurred kidney and muscle samples. Analyst, 126: 641-646.

6. Heitzman, RJ., editor. (1994) Veterinary drug residues. Residues in Food Producing Animals and their Products: Reference Materials and Methods. 2 $2^{\text {nd }}$ ed. Oxford: Commission of the European Communities, Blackwell Scientific Publications.

7. Mariel, G.P., Rapallini, M.L., Tina, Z., Elferink, J.W., Oostra-Van Dijk, S. and Alexander, J.W. (2010) Screening methods for detection of antibiotic residues in slaughter animals: Comparison of the EU-four plate method, the Nouws antibiotic test and the Premi ${ }^{\mathrm{R}}$ test (applied to muscle and kidney). Food Addit. Contam., 28(1): 26.

8. Heshmati, A. (2015) Impact of cooking procedures on antibacterial drug residues in foods: A review. J. Food Qual. Hazards Control, 2: 33-37.

9. Heshmati, A., Salaramoli, J., Kamkar, A., Hassan, J. and Jahed, G.H. (2014) Experimental study of the effects of cooking methods on tilmicosin residues in chicken. J. Vet. Res., 69: 283-290.

10. Lei, T., Salma, K. and Stephane, B. (2017) Effect of thermal treatments on the degradation of antibiotic residues in food. Crit. Rev. Food Sci. Nut., 57(17): 3760-3770.

11. Hassani, M., Lazaro, R., Perez, C., Condon, S. and Pagan, R. (2008) Thermostability of oxytetracycline, tetracyclines, and doxycycline at ultrahigh temperatures. $J$. Agric. Food Chem., 56: 2676-2680.

12. Hsieh, M.K., Shyu, C.L., Liao, J.W., Franje, C.A.,
Huang, Y.J., Chang, S.K., Shi, P.Y. and Chou, C.C. (2011) Correlation analysis of heat stability of veterinary antibiotics by structural degradation, changes in antimicrobial activity and genotoxicity. Vet. Med., 56: 274-285.

13. Franje, C.A., Chang, S.K., Shyu, C.L., Davis, J.L., Lee, Y.W., Lee, R.J., Chang, C.C. and Chou, C.C. (2010) Differential heat stability of amphenicols characterized by structural degradation, mass spectrometry and antimicrobial activity. J. Pharm. Biomed. Anal. 53: 869-877.

14. Traub, W.H. and Leonhard, B. (1995) Heat stability of the antimicrobial activity of sixty-two antimicrobial agents. $J$. Antimicrob. Chemother, 35: 149-154.

15. Papapanagiotou, E.P., Fletouris, D.J. and Psomas, E.I. (2004) Effect of various heat treatments and cold storage on sulphamethazine residues stability in incurred piglet muscle and cow milk samples. Anal. Chim. Acta., 529: 305-309.

16. Abou-Raya, S., Shalaby, A.R., Salama1, N.A., Emam, W.H. and Mehaya, F.M. (2013) Effect of ordinary cooking procedures on tetracycline residues in chicken meat. J. Food Drug Anal., 21: 80-86.

17. Rose, M.D., Bygrave, J., Farrington, W.H.H. and Shearer, G. (1996) The effect of cooking on veterinary drug residues in food: 4.Oxytetracycline. Food Addit. Contam., 13: 275-286.

18. Nonga, H.E., Mariki, M., Karimuribo, E.D. and Mdegela, R.H. (2009) Assessment of antimicrobial usage and antimicrobial residues in broiler chickens in Morogoro municipality, Tanzania. Pak. J. Nutr., 8: 203-207.

19. Clinical Laboratory Standard Institute (CLSI). (2011) Performance Standards for Antimicrobial Susceptibility Testing. Clinical and Laboratory Standards Institute, Wayne, PA. p18-20.

20. Javadi, A., Mirzaei, H. and Khatibi, S.A. (2009) Effect of roasting process on antibiotic residues in edible tissues of poultry by FPT plate. J. Anim. Vet. Adv., 8: 2468-2472.

21. Van Hue, H., Li, M., Muhammad, A.K., Chun, B.L. and Hong, Z.G. (2013) Effect of cooking methods on tetracycline residues in pig meat. Afr. J Pharm. Pharm., 7: 1448-1454.

22. Al-Ghamd, M.S., Al-Mustafa, Z.H., El-Morsy, F., Al-Faky, A., Haider, I. and Essa, H. (2000) Residues of tetracycline compounds in poultry products in the eastern province of Saudi Arabia. Public Health, 114: 300-304

\section{$* * * * * * * *$}

